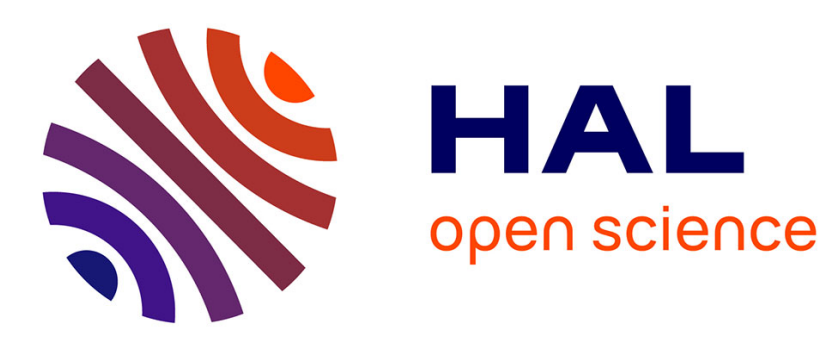

\title{
The influence of chromium additions on order and ductility in Fe3Al intermetallic
}

D. Morris, M. Dadras, M. Morris

\section{To cite this version:}

D. Morris, M. Dadras, M. Morris. The influence of chromium additions on order and ductility in Fe3Al intermetallic. Journal de Physique IV Proceedings, 1993, 03 (C7), pp.C7-429-C7-434. 10.1051/jp4:1993766 . jpa-00252186

\section{HAL Id: jpa-00252186 https://hal.science/jpa-00252186}

Submitted on 1 Jan 1993

HAL is a multi-disciplinary open access archive for the deposit and dissemination of scientific research documents, whether they are published or not. The documents may come from teaching and research institutions in France or abroad, or from public or private research centers.
L'archive ouverte pluridisciplinaire HAL, est destinée au dépôt et à la diffusion de documents scientifiques de niveau recherche, publiés ou non, émanant des établissements d'enseignement et de recherche français ou étrangers, des laboratoires publics ou privés. 


\title{
The influence of chromium additions on order and ductility in $\mathrm{Fe}_{3} \mathrm{Al}$ intermetallic
}

\author{
D.G. MORRIS, M. DADRAS and M.A. MORRIS
}

Institute of Structural Metallurgy, University of Neuchâtel, 2000 Neuchâtel, Switzerland

\begin{abstract}
It has previously been shown that the addition of $\mathrm{Cr}$ to the $\mathrm{Fe}_{3} \mathrm{Al}$ alloy can lead to improvements in ductility. Initial interpretations of this effect were based on changes in the fault energies and dislocation configurations, but recently the influence of environmental attack has been invoked. In the present study the role of $\mathrm{Cr}$ and other elemental additions on the state of order, dislocation dissociations and configurations, and on ductility has been examined under conditions where environmental attack should not be important. The addition of $\mathrm{Cr}$ is shown to have only a minor affect on ordering kinetics, fault energies and dislocation configurations. However, for the alloys generally considered, containing $28 \% \mathrm{Al}$, it is shown that the ordered state and microstructure depends sensitively on the precise composition and heat treatments given. In particular, small amounts of solute elements such as B can lead to the appearance of two-phase ordered-disordered microstructures over a wide temperature range, to the appearance of imperfect long range and short range order, and to major changes in the kinetics of ordering and disordering. The mechanical properties achieved are shown to depend critically on the extent and distribution of disorder (the long range order parameter, the extent of short range order, the presence and distribution of thick disordered domain walls) and this factor may explain much of the variability in properties reported between similar alloys. By way of example, the presence of short range order will confine dislocations to well-defined shear planes, concentrating shear and inducing early failure; disordered domain walls will dissociate superdislocations thereby spreading shear homogeneously; the ordered domains/disordered walls morphology will lead to particle-dispersion hardening.
\end{abstract}

\section{INTRODUCTION}

Iron aluminides based on both the $\mathrm{Fe}_{3} \mathrm{Al}$ intermetallic and the $\mathrm{FeAl}$ intermetallic are currently receiving extensive study as high temperatures steels with advantages over other iron base alloys of lower density, high specific strengths and moduli, and good oxidation, and in certain environments, corrosion resistance. The alloys based on $\mathrm{Fe}_{3} \mathrm{Al}$ are generally stronger than those based on $\mathrm{FeAl}$, at least at temperatures where they maintain the $\mathrm{DO}_{3}$ ordered state (1), and thus have interest for certain applications even though their density advantage and oxidation resistance may not be as good as that of the FeAl materials.

The present work is part of a larger study looking at the factors that determine the structural stability of the $\mathrm{DO}_{3}$ state for $\mathrm{Fe}_{3} \mathrm{Al}$ based alloys, and also at the factors that control the strength, both at room temperature and at high temperature. It is known that the additions of certain alloying elements, especially such as $\mathrm{Si}, \mathrm{Ti}$ and $\mathrm{Mo}$, can significantly increase the critical temperature $\mathrm{T}_{\mathrm{c}}$ for disordering of the $\mathrm{DO}_{3}$ phase (2). In fact selective control of this critical temperature according to application temperature could be of interest since these alloys are generally stronger near the critical temperature where a highly imperfect ordered state will exist (1). Many of these alloying elements are of further 
use since they can lead to solution strengthening or to precipitate strengthening (3). An additional effect of alloying with such elements may in fact be to modify the kinetics and even the mode of the ordering transformation (4), and it is this claim that has, in part, stimulated the present study. At the same time, there are many ways in which a perfectly or imperfectly ordered state may bring about strengthening and it not at all clear which of many hypotheses are of importance, both at room temperature as well as at high temperatures. The present study considers also some of these strengthening modes.

\section{EXPERIMENTAL DETAILS}

The work described here has been carried out on several alloys of $\mathrm{Fe}_{3} \mathrm{Al}$ base. All these alloys have a base composition of $\mathrm{Fe}-28 \% \mathrm{Al}$ (atomic percent) to which $4-5 \% \mathrm{Cr}$ is often added to improve ductility and corrosion resistance, based on earlier US studies. In one case $1 \%$ of the compound phase $\mathrm{TiB}_{2}$ was added, essentially to control the grain size during high temperature recrystallizing treatments. In other cases, various additions of elements such as $\mathrm{Si}$ or $\mathrm{Nb}$ have been made to improve the high temperature limit of the alloys.

These ordering and disordering behaviours of these materials have been examined both after furnace treatments, followed by a rapid quench, as well as dynamically using a DSC system and by in situ annealing in a TEM. Mechanical testing has been carried out on several materials in various ordered states by both compression and by tensile testing at temperatures over the range room temperature to $700^{\circ} \mathrm{C}$. In order to understand the mechanical behaviour observed, the deformed materials have been examined by TEM.

\section{RESULTS}

Several aspects of ordering behaviour and mechanical response of the iron aluminides are discussed briefly here. Further details of some of these points are treated in more detail elsewhere (5).

Two ordered states are possible at compositions of about $25-30 \% \mathrm{Al}$, namely the $\mathrm{B} 2$ ordered state at temperatures up to about $100^{\circ} \mathrm{C}$, and below about $550^{\circ} \mathrm{C}$ the ordered $\mathrm{DO}_{3}$ state. The change from $\mathrm{DO}_{3}$ to $\mathrm{B} 2$ is a second order phase change and $\mathrm{DO}_{3}$ order is expected to reduce continuously as the critical temperature for disordering $\left(T_{c}\right)$ is approached.

Fig. 1 shows DSC curves that follow changes occurring as alloys are heated and cooled over the $\mathrm{DO}_{3}$ $\mathrm{B} 2$ phase change. For the simple ternary alloy there are sharp changes seen near $550^{\circ} \mathrm{C}$, defining the value of $T_{c}$. Both during heating and during cooling for this alloy the order-disorder change occurs rather intensely over a $10-20^{\circ} \mathrm{C}$ interval. The enthalpy of disorder, represented by the area of the peak relative to the baseline, is about $17 \mathrm{~J} / \mathrm{g}$ for this material. Adding alloying elements can change several characteristics, for example the value of $\mathrm{T}_{c}$ (for example adding $1 \%$ Mo raises $\mathrm{T}_{c}$ by about $25^{\circ} \mathrm{C}$ ), the sharpness of the phase change (such that the sharp reaction over $10-20^{\circ} \mathrm{C}$ is broadened as a shallower peak over $20-50^{\circ} \mathrm{C}$ ). The disordering enthalpy should not change significantly since the elementary $\mathrm{Fe}-$ Al bond energy is hardly changed on alloying slightly. The change in measured enthalpy over the $300-$ $650^{\circ} \mathrm{C}$ temperature range (for example in the case of the complex alloy illustrated in Fig. 1 the disordering enthalpy is reduced to about $8 \mathrm{~J} / \mathrm{g}$ ) is a sign that the initial state was incompletely ordered or that the final high temperature state is not yet disordered.

The changes in ordering and microstructural morphology occurring on heating or cooling have been followed by in situ TEM studies, illustrated in Fig. 2, which follow qualitatively the homogeneous disordering and the heterogeneous formation of disorder at domain walls. Such heterogeneous changes, summarised in Fig. 3, confirm that disordering occurs sharply in binary Fe-28Al, at the temperature indicated by DSC, but that in complex alloys a weak order can be retained at much higher temperatures than the major disordering transition occurring at $550-600^{\circ} \mathrm{C}$ as indicated by DSC.

The influence of minor alloying additions was particularly marked in an alloy containing a small amount of Titanium and Boron (5), and especially after recrystallization heat treatments at very high temperatures where significant amounts of these elements remained in solution. For this material and 
state a second, disordered phase remained at the domain boundaries even after prolonged ordering treatments down to fairly low temperatures. Fig. 4 shows this material in comparison with a simple ternary alloy where the domain boundaries are the normal shear-fault boundaries. The retention of this two-phase state up to high temperatures was detected by DSC as a sharp, homogeneously-disordering peak near $550^{\circ} \mathrm{C}$ and a second broad peak at temperatures of about $560-620^{\circ} \mathrm{C}$ corresponding to the higher temperature disordering of the B2 ordered regions.

Mechanical properties have been analysed in detail (5) and only a brief overview is given here. Alloys containing $\mathrm{Cr}$ normally show better ductility than the equivalent $\mathrm{Fe}-28 \% \mathrm{Al}$ alloys without $\mathrm{Cr}$. Since superdislocation partial separations are essentially the same in both alloys the APB energies are confirmed to be unaffected by the addition of $\mathrm{Cr}(5)$ and hence we deduce that the better ductility is mostly due to the environmental protection offered by the $\mathrm{Cr}$ (3). This conclusion is apparently confirmed when testing under conditions where environmental attack is avoided when the $\mathrm{Cr}$-free and Cr-containing alloys show very similar ductilities (5).

In view of the limited space available here, the role of various dislocation mechanisms in controlling strength, for example the high strength found near $T_{c}$ and the role of alloying on strength, will not be discussed here. One particular strengthening mechanism identified will be presented here by way of example. Many of the $\mathrm{Fe}-28 \% \mathrm{Al}$ alloys tested here show higher strength than the $\mathrm{Fe}-28 \% \mathrm{Al}-4 \% \mathrm{Cr}$ reference alloy, as illustrated in Fig. 5. Such strengthening has been confirmed over a wide range of grain sizes, and shows that the strengthening due to refinement of the grain size is a rather minor contribution over the range of grain sizes considered, about 50 to $250 \mu \mathrm{m}$. These strong alloys all have the two phase "superalloy" like structure composed of ordered domain interiors and disordered domain walls, as illustrated in Fig. 4. The additional strengthening of these materials can thus be attributed to either pulling superdislocations through the ordered-plus-disordered composite, as in the case of nickel-base superalloys, or to the channelling of single dislocations through the disordered matrix if the ordered particles are not cut. These two theories can be modelled as:

$$
\sigma=\left(m \gamma_{\mathrm{APB}} / 2 b\right)\left\{\left(\gamma \phi f / \mu b^{2}\right)^{1 / 2}-\mathrm{f}\right\}
$$

for the case of paired superdislocations moving through the ordered particles: here $\mathrm{m}$ is the Taylor factor $(=2-3)$; $\gamma_{\mathrm{APB}}$ is the APB energy of the B2 type APB if we consider the fault between the first and second dislocations $\left(=85 \mathrm{~mJ} / \mathrm{m}^{2}\right) ; b$ is the Burgers vectror $\left(=2.5 .10^{-10} \mathrm{~m}\right)$; and $\mu$ is the shear modulus $(=70 \mathrm{GPa})$. In the case where we consider dislocations moving in the disordered wall channels the strengthening can be described by an Orowan model:

$$
\sigma=m \mu b / \lambda=m \mu b /\left\{\phi\left(f^{-1 / 3}-1\right)\right\}
$$

where $\lambda$ is the channel spacing. In these equations, $\phi$ is the size of the ordered domains and $f$ is the

\begin{tabular}{|c|c|c|c|c|c|c|}
\hline \multicolumn{7}{|c|}{$\begin{array}{l}\text { Paired superdislocations cutting ordered particles } \\
\text { Ordered domain/disordered wall strengthening (MPa) }\end{array}$} \\
\hline $\begin{array}{c}\text { Domain size(nm) } \\
\phi\end{array}$ & $\begin{array}{l}\text { Ordered } \\
\text { fraction } f\end{array}$ & 0.4 & 0.5 & 0.7 & 0.9 & 0.95 \\
\hline $\begin{array}{l}50 \\
100 \\
150\end{array}$ & & $\begin{array}{l}95 \\
205 \\
290\end{array}$ & $\begin{array}{l}85 \\
210 \\
300\end{array}$ & $\begin{array}{l}55 \\
200 \\
\mathbf{3 1 0}\end{array}$ & $\begin{array}{l}15 \\
180 \\
305\end{array}$ & $\begin{array}{l}5 \\
175 \\
300\end{array}$ \\
\hline
\end{tabular}
volume fraction of ordered material. The strengthening estimated by these models is shown below.

\begin{tabular}{|ccccccc|}
\hline \multicolumn{7}{|c|}{$\begin{array}{l}\text { Single dislocations in wall channels } \\
\text { Ordered domain/disordered }\end{array}$} \\
& Oall strengthening (GPa) & \\
\hline $\begin{array}{c}\text { Domain size(nm) } \\
0\end{array}$ & $\begin{array}{c}\text { Ordered } \\
\text { fraction } \mathrm{f}\end{array}$ & 0.4 & 0.5 & 0.7 & 0.9 & 0.95 \\
\hline 50 & & & & & & \\
100 & & 2.5 & 3.4 & 6.8 & 22 & 44 \\
150 & 1.26 & 1.7 & 3.4 & 11 & 22 \\
& & 0.84 & 1.1 & 2.2 & 7 & 15 \\
\hline
\end{tabular}


The strengthening increments can be reasonably compared with the stress differences between the fully ordered $\mathrm{Fe}_{3} \mathrm{AI}-\mathrm{Cr}$ alloy and the partially disordered $\mathrm{Fe}_{3} \mathrm{Al}$ alloys: in these cases (Fig. 5) the stress increments obtained are of the order of $100-350 \mathrm{MPa}$, according to the $\mathrm{Fe}_{3} \mathrm{Al}$ alloy considered. For these materials the domain size is typically $150-300 \mathrm{~nm}$, and the fraction of highly ordered phase is in the range $0.6-0.9$. The strength predicted by the "superdislocation" model is seen to be insensitive to the precise fraction ordered, and will take values in the range $310-155 \mathrm{MPa}$ for the experimental range of domain sizes. The strength predicted by the "channelling" model is much higher, of the order of $500 \mathrm{MPa}$ to $5 \mathrm{GPa}$, and hence seems unlikely to be the mechanism operating.

Further evidence of the dislocation mechanism controlling strengthening is provided by examination of the deformation microstructure, Fig. 6, which confirms that the ordered domains are indeed sheared by the dislocations, as expected from the "superdislocation" strengthening model. Close examination of the dislocation configurations shows that the dislocations are in fact uncoupled after a small amount of strain as single dislocations. The domain volumes are therefore sheared by B2 APB faults, as considered in the numerical evaluation of this model.

\section{CONCLUSIONS}

There is still much to be understood about the ordered state and deformation mechanisms in $\mathrm{Fe}_{3} \mathrm{Al}$ based alloys. The state of order developed, as well as the kinetics of change during annealing, depends sensitively on the alloy composition when the more complex alloys of significant interest for application are considered. Many strengthening mechanisms are expected to operate, depending on the precise degree of order, and on its homogeneity throughout the material. In addition to those mechanisms that depend on order destruction (either long range or short range) by the passage of an imperfect dislocation, and those that depend on cross slip to either create obstacles or to avoid them, other mechanisms that may be assimilated with order particle strengthening can also operate, and may lead to significant material hardening. The role of each of these mechanisms on plastic behaviour during both fast, laboratory straining and during slow, creep-like conditions should be considered.

\section{ACKNOWLEDGEMENTS}

Some of the material was supplied by C.T. Liu and C. G. McKamey of Oak Ridge National Laboratory, USA, and other materials supplied by M. Nazmy of ABB, Switzerland. We gratefully thank these people for their help. Part of this work was supported by a Swiss National Science Foundation grant, and part by the Swiss Priority Programme on Materials.

\section{REFERENCES}

1. C.G. McKamey, J.A. Horton and C.T. Liu, Mat. Res. Soc. Symp. Proc. Vol. 81, Materials Research Society, Pittsburgh, 321 (1987).

2. R.T. Fortnum and D.E. Mikkola, Mater. Sci. and Eng., 91, 223 (1987).

3. C.G. McKamey, P.J. Maziasz and J.W. Jones, J. Mater. Res., Z, 2089 (1992).

4. P.J. Maziasz, C.G. McKamey, O.B. Cavin, C.R. Hubbard and T. Zacharia, High Temperature Ordered Intermetallic Alloys, Materials Research Society Fall Meeting, in press (1992).

5. D.G. Morris, M.M. Dadras and M.A. Morris, Acta Metall. et Mater., 41, 97 (1993). 


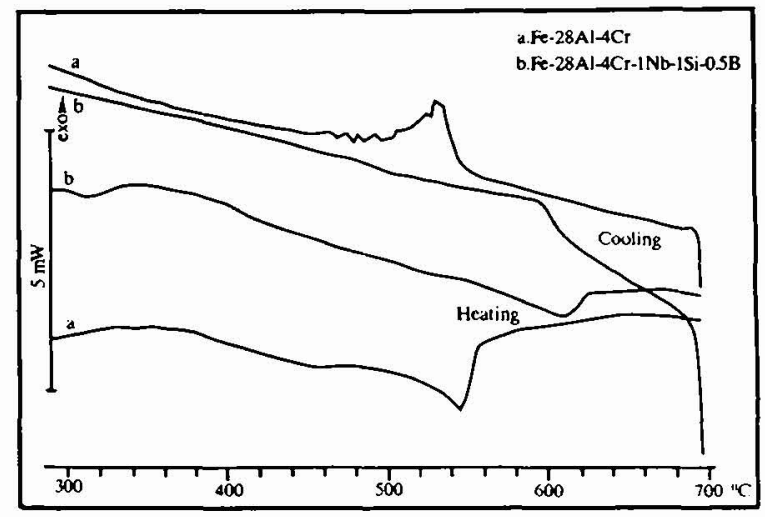

Fig.1: $\quad$ DSC curves illustrating changes occurring as $\mathrm{Fe}_{3} \mathrm{Al}$ alloys are heated and cooled over the temperature range $20-700^{\circ} \mathrm{C}$ at a rate of $10^{\circ} \mathrm{C} / \mathrm{s}$.
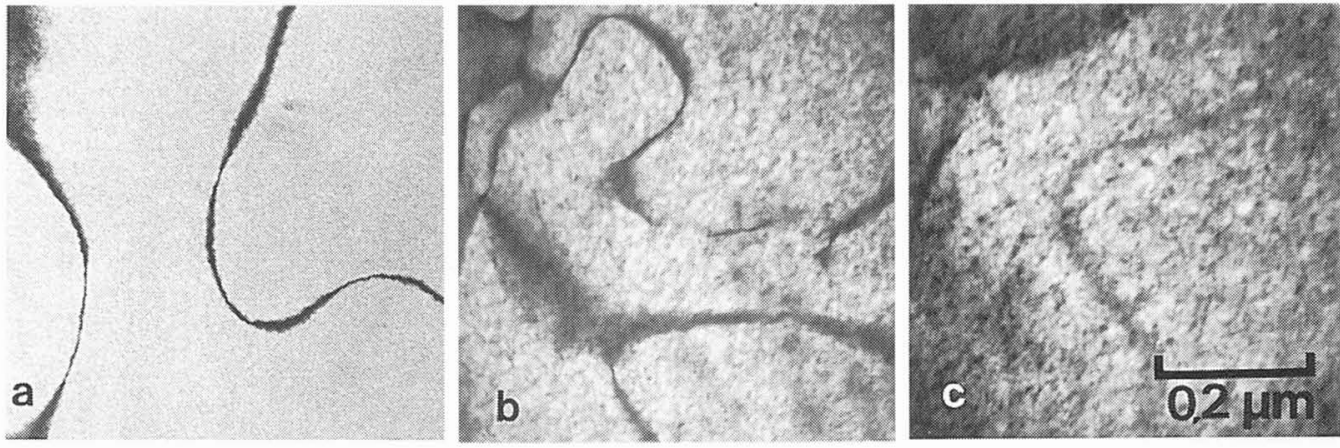

Fig. 2: Transmission electron micrographs illustrating changes in domain structure in a binary $\mathrm{Fe}-28 \% \mathrm{Al}$ alloy ordered at $500^{\circ} \mathrm{C}-(\mathrm{a})$; after reheating to $520^{\circ} \mathrm{C}-(\mathrm{b})$; and after reheating to $560^{\circ} \mathrm{C}-(\mathrm{c})$.

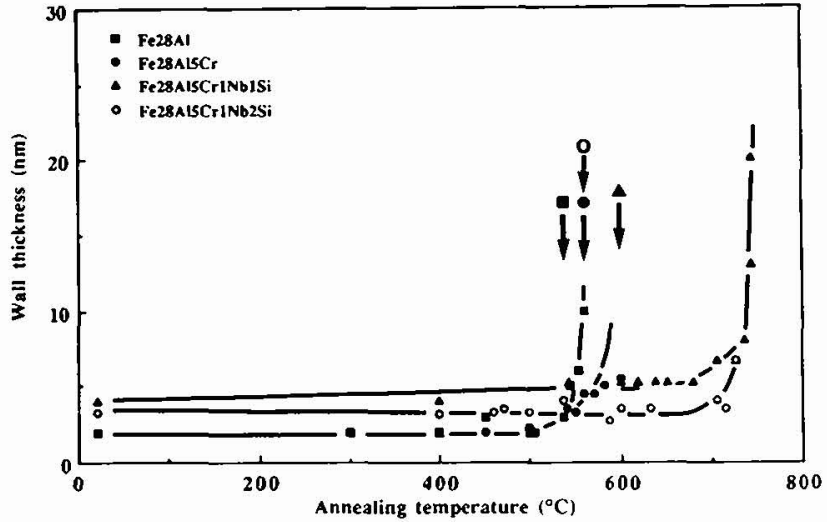

Fig.3: $\quad$ Measurements of domain wall thickening for simple $\mathrm{Fe}_{3} \mathrm{Al}$ and complex $\mathrm{Fe}_{3} \mathrm{Al}+\mathrm{Cr}+\mathrm{X}$ alloys. Disordering temperatures measured by DSC are indicated by arrows. 

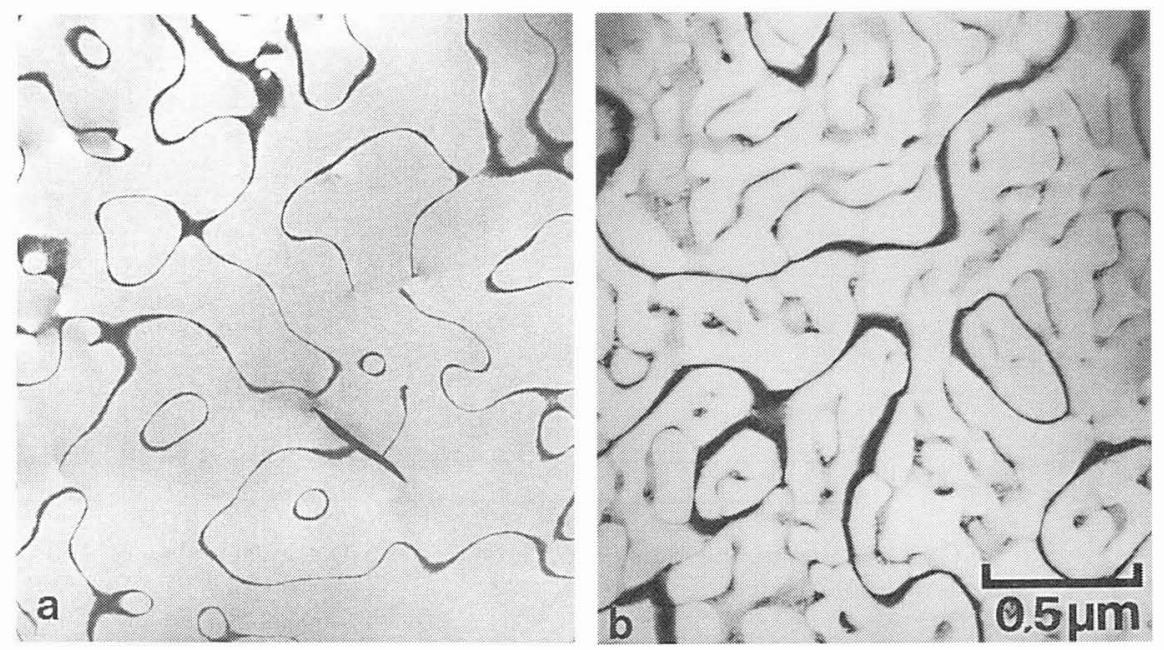

Fig. 4: $\quad \mathrm{DO}_{3}$ domain structure after annealing at $500^{\circ} \mathrm{C}$, in a simple $\mathrm{Fe}_{3} \mathrm{AlCr}$ alloy (a) and a binary $\mathrm{Fe}_{3} \mathrm{Al}$ alloy with a small addition of $\mathrm{TiB}_{2}(\mathrm{~b})$, showing single ordered phase and biphase ordered+disordered, respectively.
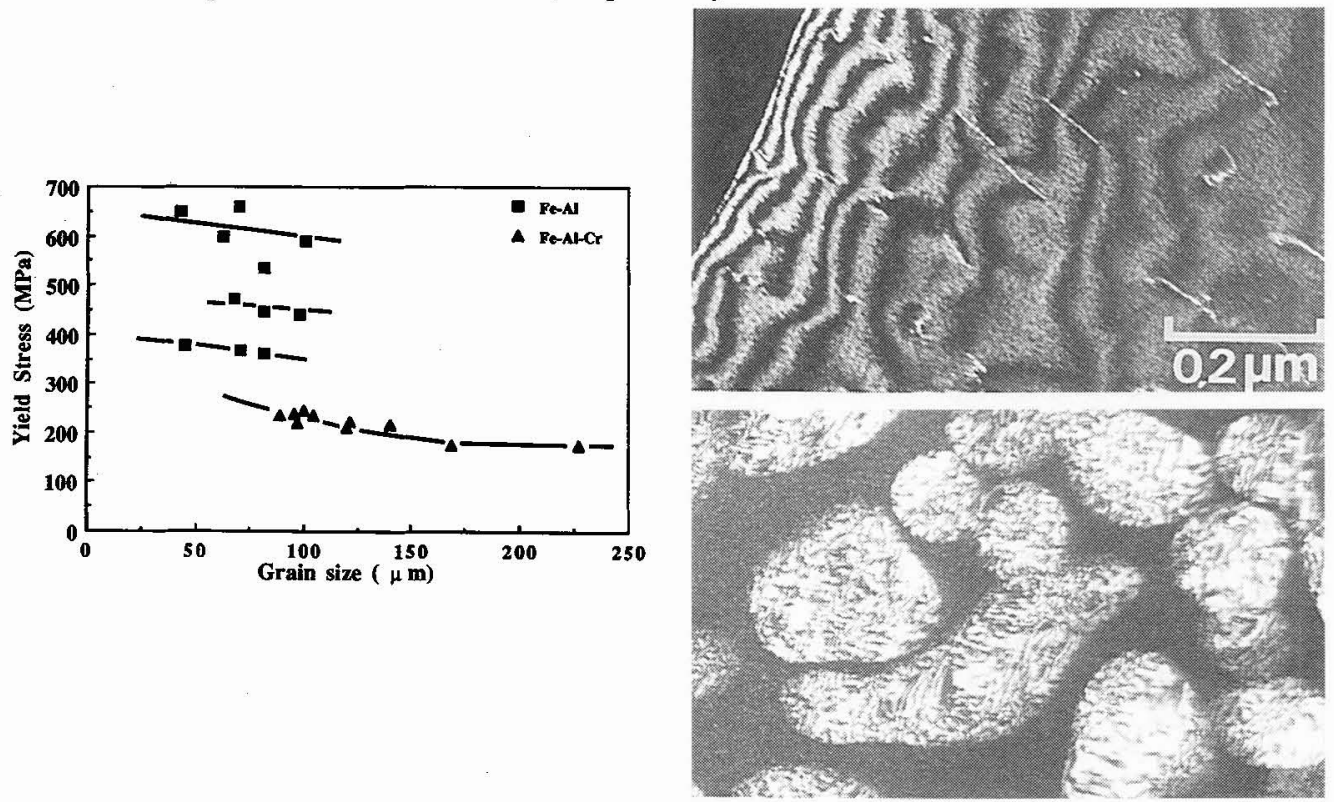

Fig. 5: $\quad$ Yield stress of $\mathrm{Fe}_{3} \mathrm{Al}$ and $\mathrm{Fe}_{3} \mathrm{AlCr}$ Fig. 6: as a function of the grain size.

Dissociated superdislocations at domain walls in bi-phase material. 